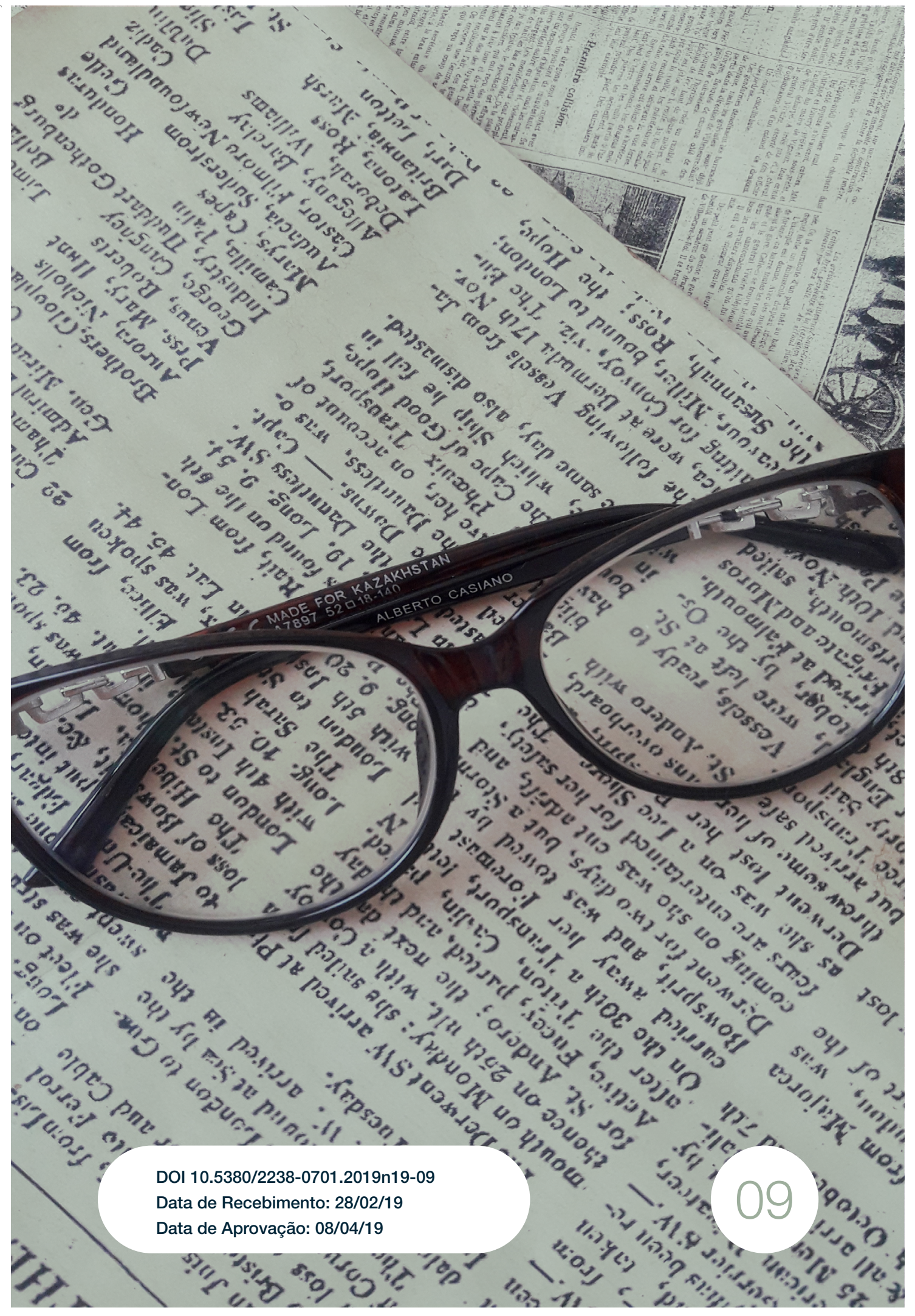


La suite à demain: gancho, folhetim e o romance-folhetim A Condesssa de Salisbury 


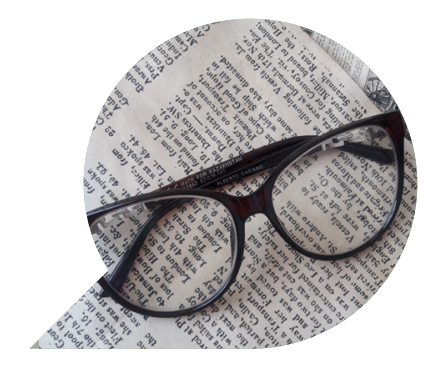

\section{La suite à demain: gancho, folhetim e o romance-folhetim A Condesssa de Salisbury ${ }^{1}$}

To be continued: cliffhanger, feuilleton and La Comtesse de Salisbury

La suite à demain: gancho, folleto y La Comtesse de Salisbury

LUÍS ENRIQUE CAZANI JÚNIOR ${ }^{2}$

Resumo: O presente trabalho apresenta notas sobre a origem e a consolidação do folhetim como uma seção localizada na extremidade inferior dos jornais franceses. Além disso, levanta-se a constituição do romance-folhetim como uma matriz de linguagem, indicando suas fases e avaliando a construção de seus ganchos. Há uma análise narrativa seguindo Propp (2012) e Mckee (2006) do gancho do primeiro capítulo do romance-folhetim A Condessa de Salisbury (1836), escrito por Alexandre Dumas. Da alteração do tamanho da folha do papel às experimentações no espaço extra, o termo "folhetim" tornou-se sinônimo de apenas uma de suas publicações, o romance-folhetim, ainda que tenha sido um espaço de textos diversos.

1 Trabalho financiado pela Fundação de Amparo à Pesquisa do Estado de São Paulo (FAPESP: 2014/10135-3). 2 Doutorando em Comunicação pela Universidade Estadual Paulista Júlio de Mesquita Filho, Faculdade de Arquitetura, Artes e Comunicação (FAAC/Unesp). Bolsista de Doutorado e de Mestrado da Fundação de Amparo à Pesquisa do Estado de São Paulo (FAPESP). E-mail: enrique.cazani@unesp.br. 
Palavras-chave: Folhetim; Romance-folhetim; Gancho; Interrupção.

Abstract: This paper presents considerations about the origin and the consolidation of the feuilleton, section located at the lower end of the French newspapers. Also, it analyzes the constitution of the roman-feuilleton as a language basis, indicating its phases and evaluating the construction of cliffhangers. There is a analysis following Propp (2012) and Mckee (2006) from the cliffhanger of the first chapter of the La Comtesse de Salisbury (1836) written by Alexandre Dumas. From the change in the size of the sheet of paper to the trials in the space added,the term "feuilleton" has become synonymous with only one of its publications, the feuilleton roman, although it has been a space of diverse texts.

Keywords: Feuilleton; Serial novel; Cliffhanger; Interruption.

Resumen: El presente trabajo presenta notas sobre el origen y la consolidación del folleto como una sección ubicada en el extremo inferior de los periódicos franceses. Además, se levanta la constitución del romance-folleto como una matriz de lenguaje, indicando sus fases y evaluando la construcción de sus ganchos. Hay un analisis siguiendo Propp (2012) y Mckee (2006) del gancho del primer capítulo de la novela La Comtesse de Salisbury (1836) escrita por Alexandre Dumas. De la alteración del tamaño de la hoja del papel a las experimentaciones en el espacio agregado, el término "folleto" se ha convertido en sinónimo de una de sus publicaciones, la novela seriada, aunque haya sido un espacio de textos diversos.

Palabras claves: Folleto; Romance folleto; gancho; interrupción

\section{Introdução}

Foram consultadas as páginas digitalizadas de jornais franceses do final do século XVIII e do início do século XIX na plataforma de acesso on-line da Biblioteca Nacional da França (BnF) para estudo sobre o gan- 
cho e a gênese do folhetim e do romance-folhetim. O resgate, leitura e discussão das colunas inaugurais do Journal des Débats, Le Siècle e La Presse gerou os apontamentos expostos neste trabalho. No percurso da investigação, foi encontrado o primeiro folhetim, as razões e a data do seu aparecimento, além do primeiro romance: A Condessa de Salisbury (1836), de Alexandre Dumas. Olhares foram lançados sobre essa obra precursora, possuindo como centro de interesse o corte de fim do capítulo de sua estreia, comparando-o com o término do primeiro capítulo de Os Três Mosqueteiros (1844), escrito pelo mesmo autor no ápice do movimento, aqui descrito e caracterizado. As funções proppianas e a tríade "expectativa, resultado e brecha" de Robert Mckee (2006) auxiliam o entendimento da sua organização narrativa e do gancho, métodos empregados neste trabalho.

Esse modo de publicação seriado de histórias pelo Jornalismo suscita polêmicas quanto à monetização: remuneração por linha desenvolvida, literatura denominada industrial pelo uso da produção racionalizada e alteração do modelo de negócio de jornais para atrair a burguesia como consumidora. Da serialidade, que pressupõe o fragmento, a interrupção e a repetição, veio o corte sistemático; da recepção inserida na dinâmica de mercado adveio a necessidade de extrair efeitos de sentido que garantissem a manutenção da aquisição; continuar significava alimentar, protelar, cumprir e "quebrar" as expectativas do leitor enquanto for rentável.

\section{Notas sobre a origem e consolidação do folhetim}

Feuilleton é a flexão de grau no diminutivo do substantivo masculino feuillet, podendo ser compreendido como uma folha de tamanho reduzido. O vocábulo define, também, uma seção localizada ao final das páginas dos jornais conhecida no Brasil como folhetim. Segundo Massaud Moisés (2013), essa palavra emergiu em 1790 e a concepção da coluna homônima atribuída a J. Louis Geoffroy³ foi lançada em 1799 pelo Journal des Débats, dirigido por Louis-François Bertin.

3 Para Massaud Moisés (2013), Jean é o primeiro nome de Louis-Geofroy, enquanto The British Cyclopaedia of the Arts, Sciences, History, Geography Literature, Natural History and Biography define Julien. 
Figura 01-02: Fac similar Journal des Débats, edições de 22 e 23 de janeiro de 1800
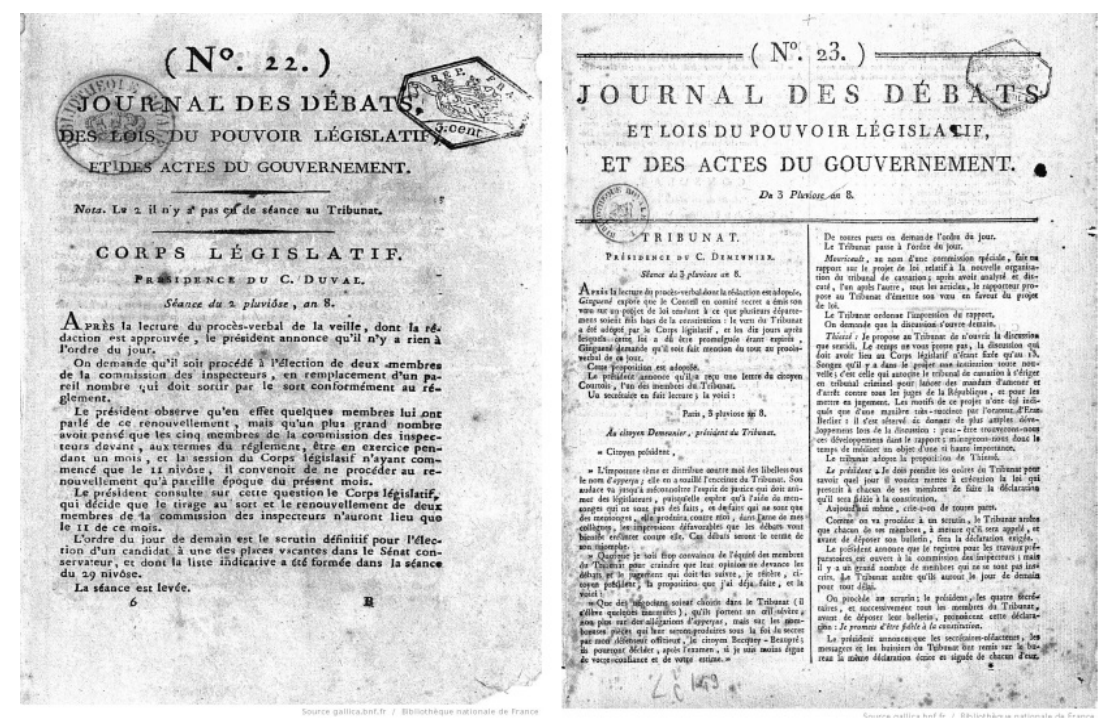

FONTE: Biblioteca Nacional da França (BnF)

Ao debruçar-se sobre as publicações desse periódico ${ }^{4}$ disponibilizadas pela Biblioteca Nacional da França (BnF), constatou-se alteração em sua diagramação na edição número $23^{5}$ publicada em 23 de janeiro de 1800. Dispostos anteriormente ${ }^{6}$ de forma corrente em coluna única conforme a figura 01 , os textos foram distribuídos em duas colunas justapostas pelas suas quatro páginas. Uma nova mudança foi detectada na edição número $28^{7}$ publicada em 28 de janeiro: demarcou-se horizontalmente a página com traço espesso, dividindo-a de maneira irregular, em uma parcela superior e outra inferior. Dessa forma, ao final do século XVIII, emitiu-se pela primeira vez um fragmento de jornal como Feuilleton.

4 Consultaram-se as edições do período compreendido entre 21 de janeiro e 21 de fevereiro de 1800 na BnF. 5 Publicação disponível em: <http://gallica.bnf.fr/ark:/12148/bpt6k415705g.image> acesso em 07.04.2015. 6 Publicação disponível em: <http://gallica.bnf.fr/ark:/12148/bpt6k4157043.image> acesso em 07.04.2015. 7 Publicação disponível em: <http://gallica.bnf.fr/ark:/12148/bpt6k415710x.image> acesso em 07.04.2015. 
Figura 03: Fac similar Journal des Débats, edições de 28 de janeiro de 1800

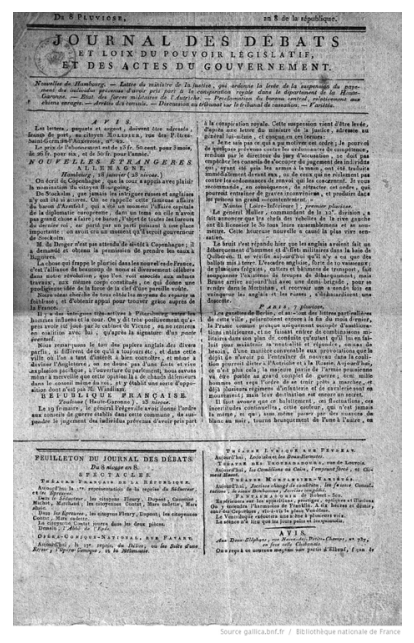

FONTE: Biblioteca Nacional da França (BnF)

De acordo com Le Livre du centenaire du Journal des Débats, a origem do folhetim está relacionada com modificações na extensão da página do jornal, como demonstra o excerto abaixo que postergou a origem do folhetim para 29 de janeiro de 1800. Contudo, como visto no cabeçalho da figura 03, a data correta é 8 pluviôse, identificada pela BnF como dia 28.

Em 23 de janeiro de 1800, ou 3 pluviôse no calendário republicano francês, o Journal des Débats é convertido para o formato de l'Éclair, pequeno i-40; contém o resumo das sessões do Tribunal e do Corpo Legislativo assinada por Baudouin. Em 25 de janeiro, ou 5 pluviôse, tudo mudou: a equipe administrativa de Bertin instala-se, com nomes conhecidos que aparecem em todos os jornais. Isto é, Dupré, Molinier e Geoffroy, não o crítico, mas Geoffroy, o funcionário a quem as cartas, encomendas e dinheiro devem ser enviados e quem recebe as assinaturas. Em 29 de janeiro, ou 9 pluviôse, o formato i-4o aumenta e cria-se a pequena seção, chamada folhetim. Foram produzidas duas edições, uma com e a outra sem o folhetim. O jornal completo, ou seja, com o folhetim, custou por departamento um franco e cinquenta a mais por trimestre. A edição dupla foi mantida até o final do ano XI. Os boletins de teatro eram, inicialmente, apenas anúncios de shows que ocorreriam no dia, com algumas avaliações. Com Geoffroy, folhetim sustenta-se com a dramaturgia (PLON; NOURRIT, 1889, p. 28, 
tradução nossa) ${ }^{8}$.

Segundo The British Cyclopaedia of the Arts, Sciences, History, Geography, Literature, Natural History and Biography, organizado por Charles Partington, Julien Louis-Geoffroy (1743-1814) foi um aficionado pelo teatro, reconhecido professor, cultuado crítico francês e premiado panegírico. Suas apreciações e suas provocações acerca da literatura, moralidade e filosofia foram registradas em inúmeras linhas publicadas em Annee Litteraire e Journal des Débats. Com sua morte em 1814, Geoffroy não vivenciou o florescimento do folhetim como espaço de recepção de obras literárias, considerado o apogeu da sua criação.

Partindo desse pressuposto, a revisão e a adequação de uma propriedade do meio de comunicação favoreceu a ocorrência de experimentações no espaço extra do jornal, dado importante da constituição não relatada pela literatura especializada. Inicialmente, existiam edições simultâneas, com a presença e ausência do folhetim como relatado no trecho citado. Posteriormente, apenas com sua presença. Atribui-se à crítica literária e ao teatro o status quo de suas forças motrizes.

É possível caracterizar o folhetim no período de formação como um espaço de publicização da cultura. Na edição de 1 de fevereiro de 1800, ele foi iniciado com os seguintes dizeres aqui traduzidos: "o preço para a inserção de anúncios, avisos, etc., é de 15 centavos por linha. Realizamos convênios com aqueles que desejam levar ao público seus artigos 9". Notabiliza-se, portanto, o seu caráter mercadológico e de agendamento social. Nas publicações iniciais, ele foi composto com textos de natureza diversa e de pequena extensão: divulgação de peças teatrais (Spectacles); matérias de política e literatura (Ephémérides politiques et litteraires), charadas (Charades), enigmas (Enigme), divulgação de livros (Notices de livres), avisos e conselhos (Avis), poemas (Logogryphe, Épi-

\footnotetext{
8 Texto original:"Dès le 3 pluviôse an VIII (23 janvier 1800), le Journal des Débats prend le format de l'Éclair, petit in-40; mails il ne contient encore qu'un résumé des séances du Tribunat et du Corps législatif; la signature de l'imprimeur est toujours celle de Baudouin. Le 5 pluviôse (25 janvier), tout est changé; le personnel administratif des Bertin, dont les noms ont paru dans tous leurs journaux d'autrefois, est installé. C'est Dupré, Molinier, puis Geoffroy, non pas Geoffroy le critique, mais Geofroy l'employé, auquel les lettres, paquets et argent doivent être envoyés, et qui reçoit les abonnements. (...) Le 9 pluviôse, le format in-4o s'allonge et devient un petit in-folio pour faire place au feuilleton. II se tirait deux éditions, l'une avec et l'autre sans le feuilleton. Le journal complet, c'est-à-dire avec le feuilleton, coùtait pour les départements un franc cinquante de plus par trimestre. La double édition s'est maintenue jusqu'a la fin de l'an XI. Bientôt le bulletin des tréatres, qui n'était d'abord que a simple annonce des spectacles du jour, contient quelques appréciations. Puis Geoffroy parait, et le feuilleton dramatique est fondé".

9 Texto original: "Le prix de insertion des annonces, avis, etc, est 15 centimes par ligne. On prendra des arrangemens avec ceux que front repéter leurs articles".
} 
gramme), venda de produtos (Bien à vendre), moda (Modes), demandas (Demandes) e informações da tesouraria nacional (Trésorerie Nationa(e); serialização que contempla textos independentes a cada veiculação, reunidos sob a mesma denominação.

Trinta e seis anos mais tarde, ao analisar as edições do período de fundação ${ }^{10}$ do jornal Le Siècle: journal politique, littéraire et d'economie sociale, concebido por Armand Dutacq, notou-se que suas publicações também continham quatro páginas, das quais três possuíam a demarcação Feuilleton. Na edição de apresentação ${ }^{11}$ divulgada em 23 de junho de 1836, Louis Desnoyers explicou a finalidade do folhetim: romper a submissão de determinados temas à política, sobre a qual se confeccionavam os jornais da época. Essa premiere expôs ao leitor a situação do momento e as mudanças buscadas através da seção.

Um conjunto de escritores especializados confeccionavam os textos, distribuídos nas divisões temáticas: Literatura Nacional (Littérature Nationale), Teatro (Théatres), Literatura Estrangeira (Littérature Etrangérs), Ciências Morais (Sciences Morales), Ciências Físicas (Sciences Physiques), Belas-Artes (Beaux-Arts), Cursos Públicos (Cours Publics), Concursos Acadêmicos (Concours Académiques), Revista Estrangeira (Revués Étrangéres), Indústria (Industrie), Turismo (Voyages), Misturas (Mélanges) e Variedades (Varietés). A apresentação destacou o relacionamento entre literatura nacional e política, campos de atuação fundados na dialética, cuja evolução é condicionada pela existência de discussões. Por meio dos folhetins, eram buscados o restabelecimento da crítica e a promoção um regimento literário.

Em sua primeira edição, publicada em primeiro de julho de 1836, foram mencionados críticos, escritores e acadêmicos selecionados para confeccionar artigos de literatura: Charles Nodier, Bibliophile Fortuoul, Michel-Raymond, Eléonore de Vaulabelle, Edouard Lemoine, Altaroche, Achille Jubinal, $\mathrm{H}$ de Latouche, Alphonse Karr, Felix Pyat, León Gozlan, Hippolyte Fortoul, Roger de Beauvoir, Henri Martin, Henri Monnier, Louis Viardot, Louis Desnoyers, Raoul-Rochette e Bory Saint-Vicent. Ao relatar sobre a inserção de textos que concernem à literatura estrangeira, o editor do prospecto ressaltou a possibilidade de conhecer, dialogar, estudar e inventariar obras. Revistas estrangeiras eram consideradas materiais

10 Consultaram-se as edições do período compreendido de primeiro a 31 de julho de 1836.

11 Publicação original disponível em: <http://gallica.bnf.fr/ark:/12148/bpt6k718312w.image.langPT.r=Le\%20Si\%C3\%A8cle\%20:\%20journal\%20politique,\%20litt\%C3\%A9raire>, acesso em 07.04.2015. 
ricos em informações e faziam sucesso entre os leitores, ganhando seção à parte. É evidente o modo como os jornais da época teciam críticas ao teatro, reconhecido como outra divisão temática do folhetim. $\mathrm{Na}$ exposição de estreia, foram apontadas as alterações pelas quais as peças de teatro passavam, tais como limites das categorias fundamentais do drama, além do emprego do excesso e do excêntrico na elaboração. A crítica dramática era considerada negligente por não promover direcionamentos aos movimentos vanguardistas.

Na divisão temática Ciências Morais, Louis Desnoyers criticou o pensamento filosófico na Era Moderna, descaracterizado pela expansão da atuação do homem nas pesquisas. Foi ampliado o interesse pelos estudos que integram o ser, considerando relacionamentos com a materialidade, a moralidade e a cidadania. Havia, ainda, assuntos históricos, geográficos, biográficos e estatísticos nessa divisão. Descobertas científicas e aplicações eram divulgadas em Ciências Físicas; informações sobre Indústria eram apresentadas sob essa chancela; as exposições, os concertos e os estudos técnicos, históricos e biográficos acerca de artistas eram classificados como Belas-Artes; as seleções públicas e programas de ensino eram inseridos em Concursos Públicos e Cursos Acadêmicos; as crônicas de viagem, costumes, curiosidades, clima e países integravam Viagens; as obras completas, trechos, novelas e festivais artísticos eram reunidos sob o título de Variedades; por fim, textos que não integravam as divisões temáticas eram denominados de Misturados ou Diversos.

No exercício analítico que compreendeu as edições do período de formação ${ }^{12}$ do La Presse, jornal criado por Émile de Girardin, constatou-se o caráter irregular do seu folhetim: há uma variação de duas a quatro páginas de edição em edição e a barra espessa horizontal não era fixa: o corpo superior invadia o rodapé. Não foi encontrado na premiere ${ }^{13}$ qualquer menção ao Feuilleton. Mas pode-se apontar como temas frequentes encontrados no período analisado: Ciência, Viagem, Indústria, Dramaturgia, Biografias e Críticas Literárias. Entre os autores que assinavam o folhetim do La Presse estão Frédéric Soulié, Alexandre Dumas, Martin Doisy e Alphonse Esquiros. Soulié foi responsável pela assinatura da primeira edição do Feuilleton do La Presse, um texto poético que engrandeceu e enobreceu o papel da seção, trecho significativo traduzido

12 Consultaram-se as edições do período compreendido entre primeiro de julho a 31 de fevereiro de 1836

13 Publicação original disponível em: <http://gallica.bnf.fr/ark:/12148/bpt6k426719v>, acesso em 07.04.2015 
e apresentado aqui: "se a impressão tivesse sido inventada há dois mil anos, se a imprensa diária tivesse existido, se o Feuilleton tivesse vivido, os romanos teriam o feito um Deus"14. Entre metáforas e alegorias, o escritor atribuiu à Revista Mercure françois (1611) como sua provável raiz. De modo geral, Soulié vislumbrou a ação do folhetim em seu artigo e concluiu: "Folhetim é um poder. A melhor prova que posso dar é que são poucos os que são lisonjeados e insultados ${ }^{15}$ ".

Ao longo do século XIX, o folhetim sofreu um processo de sistematização que impossibilita atribuí-lo a chancela unívoca de entretenimento como era no início. Passou-se a ser inserido no espaço obras literárias de modo fragmentado, modo de publicação que levou à constituição de um gênero do discurso: o romance-folhetim. O periódico, como veículo de comunicação, contempla com objetividade os eventos do cotidiano. Sua apresentação em si produz um sentido de completude, embora possam existir desdobramentos, gerando novas totalidades. No romance-folhetim não é diferente, como se segue.

\section{Romance-folhetim: origem, fases e características}

Define-se romance-folhetim como história seriada que foi criada para ser publicada na seção Feuilleton. Existem diversas tentativas de estabelecer o marco de origem do fenômeno. Arnold Hauser (1972) credita à Revue Deux Mondes a responsabilidade da serialização de histórias.

La Presse e o Siècle são os primeiros jornais diários a publicar séries de artigos, mas a ideia de publicar um romance em folhetins não lhe pertence. Vem já de Véron, que foi o primeiro a pô-la em prática na sua Revue de Paris fundada em 1829. Buloz aproveita-se dela na Revue des Deux Mondes e publica sob esta forma, entre outras coisas, romances de Balzac (HAUSER, 1972, p. 894).

Escrita por Honoré de Balzac, La vieille fille é considerada por alguns críticos como a primeira obra da seção. Contudo, ao debruçar-se sobre as publicações do La Presse de 23 de outubro a 4 de novembro

14 Texto original:"Si l'imprimerie eùt eté inventée il y a deux mille ans, si la presse quotidienne eùt existé, si le Feuilleton eùt vécu, les Romains en enssent fait un dieu".

15 Texto original:"Le Feuilleton est une puissance. La meilleure preuve que j'en puisse donner, c'est qu'il y en a peu qui soient plus flattés et plus insultées". 
de 1836, denotou-se sua inserção na parte superior do periódico, na coluna Varietés. Há, ainda, Lazarrillo de Tormes, publicada de forma seriada no folhetim do Le Siècle a partir de 5 de agosto de 1836. Nesta pesquisa, La Comtesse de Salisbury ou A Condessa de Salisbury em português é tido como primeiro romance-folhetim francês, escrito por Alexandre Dumas e publicado a partir de 15 de julho de 1836 no La Presse. Até tal data, não foram encontrados romances no Le Siècle e no Journal des Débats.

Em Folhetim: uma história, Marlyse Meyer (1996) indicou três momentos distintos da produção folhetinesca, considerando reverberações das revoluções burguesas de 1830 e 1848, o golpe de Estado de 1851 e a Guerra Franco-Prussiana de 1870. No ínterim compreendido entre os anos de 1836 e de 1850, os escritores Eugène Sue, Alexandre Dumas e Honoré de Balzac estabeleceram o arcabouço do romance-folhetim com narrativas históricas e sociais dotadas de heróis ideais; de 1851 a 1871, sob a égide de Luís Napoleão, Ponson du Terrail criou a estrutura rocambolesca ${ }^{16}$, alusão ao anti-herói Rocambole, com aventuras sob a forma de série, no tempo em que surgiram as vendas unitárias do Le Petit Journal; e, por fim, de 1871 a 1914, o pensamento conservador, sentimental, sensacionalista e, agora, naturalista, ressoou em textos de Émile Richebourg e Xavier de Montepín que evocaram heróis-vítimas. Após conferir os limites, Meyer (1996) atribuiu a Ėmile de Girardin a responsabilidade pela criação do gênero. Como editor do jornal La Presse, foi o responsável pelo barateamento das assinaturas, utilizando a publicidade e tornando a burguesia seu público consumidor. O gesto possibilitou o apogeu da literatura nos rodapés.

A almejada adequação ao grande público, a necessidade do corte sistemático num momento que deixe a atenção em "suspense" levam não só a novas concepções de estrutura (por exemplo, o problema dos fins dos capítulos ou de série, a distribuição da matéria seguindo aquele esquema iterativo tão bem evidenciado por Eco) como a uma simplificação na caracterização dos personagens, muito romântica na sua distribuição maniqueísta, assim como a uma série de outros cacoetes estilísticos. Verifica-se, além disso, genial adaptação à técnica do "suspense" e ao rápido e amplo ritmo folhetinesco dos grandes temas românticos: o herói vingador ou purificador, a jovem desflorada

16 Meyer (1996) indica como características: exagero, paródia, apropriação de matrizes de linguagem e metalinguagem 
e pura, os terríveis homens do mal, os grandes mitos modernos da cidade devoradora, a História e as histórias fabulosas etc (MEYER, 1996, p. 31).

A partir de compêndio, José Alcides Ribeiro (1996) elencou propriedades do romance-folhetim. Com Sainte-Beuve foram indicadas duas consequências da monetarização por linha dos escritores: histórias extensas e repleta de diálogos; em Régis Messac, ele postulou sobre a similaridade do gênero como o melodrama e o romance picaresco, destacando a ausência da interioridade da personagem, mecanismos que chamem a atenção e seduzam os leitores, como ganchos e o próprio título do romance, a presença de retomadas com atualizações das ações, exposições grandiosas, inspirações no romance histórico, utilização de objetos mágicos, epítetos para referenciar personagens, criminalidade, miséria, acaso e conflitos sociais como temas, além do excesso de ações com consequências negativas e construção com interação do diretor do jornal e público; discutindo notas de Pierre Noriey, Ribeiro (1996) dissertou sobre o reconhecimento da personagem pelo detalhamento físico, além de denotar descrições mínimas e cenários recorrentes; seguindo Jean-Louis Bory, retratou as consequências da serialidade, efeitos da interrupção no desenvolvimento da história e abertura de linhas narrativas diversas, por fim, com Umberto Eco, vislumbrou aspectos ideológicos e fundamentais, como mistura de fantasia e realidade, além da estrutura sinusoidal.

\section{La suite à demain: o gancho no romance-folhetim}

A locução francesa "la suite à demain" era utilizada no encerramento de capítulos do romance-folhetim significando "continua amanhã". Essa marcação integrava a sistematização do corte, cuja ruptura ocorria a partir de uma situação que despertava curiosidade para manter a continuidade da fruição. Em estudo sobre a serialidade desse gênero do discurso, Jean Louis Bory (1966, p.13) afirmou: "deve-se não só apoiar nessa fragmentação, mas alimentar-se dela, extrair efeitos de sentido dessa divisão" e "é necessário que cada publicação seja vislumbrada como totalidade de sentido, satisfazendo e renovando a expectativa do 
leitor, criando o suspense ${ }^{17 "}$.

Você estava falando de arte, aqui está a arte. A arte do desejo e da espera. Você tem, suponho eu, um personagem chamado Senhor Arthur que interessa ao público. Faça manobras com ele de modo que nenhuma ação ou efeito seja perdido. Ao final da publicação, uma situação crítica, um vocábulo misterioso e Arthur, claro, com a presença de Arthur. Quanto mais o público apreciar Arthur, mais deverá ser utilizado como chamariz ${ }^{18}$ (BORY,1966, p. 13-14).

Na historicização do folhetim, Meyer (1996) exaltou esse poder da construção textual de Eugène Sue a partir do excerto de Liliane Durand Dessert:

O romance folhetim de E.Sue põe em ação uma técnica de exacerbação do desejo - desejo de saber - num contexto sadomasoquista: o leitor fica preso, pela periodicidade, no "acme" de uma posição "sublime", no sentido etimológico da palavra, isto é, encontrar-se nos confins de um saber incessantemente prometido, mas sempre adiado: "Eu digo, para fazer esperar aquilo que escolhi não dizer"; donde o deleite, de certo modo masoquista, do leitor, que aceita ser sempre frustrado, sempre desconcertado, balançado ao bel-prazer do romancista entre a deliciosa angústia e a hipotética esperança: "E o desejo cresce quando se afasta o efeito", esse verso do velho Corneille sugere muito bem como toda manipulação proteladora contém subentendidos eróticos (DESSERT apud MEYER, 1996, p. 78-79).

Na tessitura da trama, quais foram os elementos empregados para despertar a vontade no leitor? Componentes provenientes do teatro grego: peripécia, reconhecimento e catástrofe. Segundo Aristóteles (1966, p. 80-81), a peripécia é "mutação dos sucessos, no contrário"; o reconhecimento é a "passagem do ignorar ao conhecer, que se faz para amizade ou inimizade das personagens que estão destinadas para a dita para a desdita"; por fim, a catástrofe é um evento negativo de im-

\footnotetext{
17 Texto original: "II doit non seulement supporter ce découpage, mais s'en nourrir, en tirer des effets" e, ainda, "II faut que l'épisode publié soit non seulement un tout - satisfasse une certaine attente du lecteur - mais renouvelle cette attente, crée ce que nous appelons aujourd'hui le suspense".

18 Texto original:"C'est surtout dans la coupe, móssieur, que le vrai feuilletoniste se retrouve. II faut que chaque número tombe bien, qu'il tienne au suivant par une espèce de cordon ombilical, qu'il appelle, qu'il donne le désir, l'impatience de lire la suite. Vous parliez d'art, tout à l'heure; l'art, le voilà. C'est l'art de se faire désirer; de se faire attendre. Vous avez, je suppose, un M.Arthur à qui vote public s'intèresse. Faites manoeuvrer ce gaillard-là de faon qu'aucun de des faits et gestes ne porte à faux, ne soit perdu pour l'effet. A chaque bout de feuilleton une situation critique, un mot mystérieux, et Arthur, toujours Arthur au bout! Plus le public auro mordu à votre Arthur, plus vous devez en tirer parti, le lui présenter comme amorce".
} 
pacto significativo. Alguns estudiosos preferem o conceito de "golpe ou lance teatral", definido por Pavis (2011, p. 287) como "ação totalmente imprevista que muda subitamente a situação, o desenrolar ou a saída da ação". São artifícios que elevam a tensão da narrativa e, consequentemente, são usados para o rompimento. Luís Enrique Cazani Júnior (2016) sintetiza essas oscilações e as rupturas de diferentes gêneros do discurso em seu estudo acerca do fenômeno do gancho. O quarto quadrante da figura 4 pode ser aplicado ao romance-folhetim, precursor das telenovelas atuais. Enquanto a tragédia possui apresentação contínua, o melodrama apresentava três atos encerrados após a conclusão do evento. Já o romance-folhetim e a telenovela encerram no auge do pulso com ponto de virada ou situação climática.

Figura 04: A tensão na tragédia, no melodrama, no cinema, na telenovela no fluxo e na recepção sob demanda para não assinantes de telenovela no Globoplay e

\section{Gshow.}

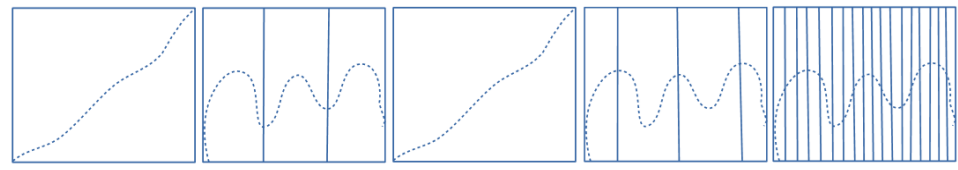

FONTE: Cazani Júnior (2016, p. 118)

Ao levantar aspectos fundamentais de Os Mistérios de Paris de Eugène Sue, Umberto Eco (2008) qualificou a produção folhetinesca como "estruturas de consolação", postulando sobre a necessidade de introduzir uma nova informação de maneira inusual, imprevista e repentina. Além disso, para Eco (2008, p. 193), há, pelo menos, duas estruturas de histórias: "as obras narrativas de curva constante (onde os diversos elementos do enredo se acumulam até criar uma tensão maximal que o desfecho fará explodir)" e "as obras de estrutura que chamaremos de sinusoidal (tensão, distensão, nova tensão, nova distensão)". Sobre a última, ressalta ainda que, "a estrutura sinusoidal resulta quando muito do entrecruzamento de vários enredos” (ECO, 2008, p. 194). Dessa forma, o centro da atenção pode ser modificado a cada publicação.

A seguir, uma leitura do primeiro capítulo do primeiro romance-fo- 
Ihetim A Condessa Salisbury, contemplando o gancho para ilustrar esta exposição.

\section{Materiais e Métodos}

A Condessa de Salisbury é considerado o primeiro romance-foIhetim francês, escrito por Alexandre Dumas e publicado no Jornal La Presse, a partir de 15 de julho de 1836. Sua introdução apresenta um estudo sobre o romance histórico, pontuando as dificuldades na elaboração desse gênero, exaltando seus principais escritores e estabelecendo a origem da obra: um documento sobre acontecimentos entre Gália e França. Nessa apresentação, não há eventos narrativos utilizados no estudo sobre a fragmentação da história. Para a compreensão do gancho foi selecionado o capítulo publicado no dia 17 intitulado Le Voeu du Héron ${ }^{19}$.

Já Os Três Mosqueteiros é um romance-folhetim francês escrito por Alexandre Dumas, publicado no Jornal Le Siecle, a partir de 15 de março de 1844. O prefácio apresenta um relato do autor acerca do seu estudo sobre as histórias que rodeiam Luís XIV. Em suas pesquisas, Dumas encontrou o livro Mémoires de $M$. d'Artagnan, situando-as no reinado de Luís XIII. Entre os fatos narrados está o encontro de M. d' Artagnan com os mosqueteiros Athos, Porthos e Aramis. Para compreensão do gancho foi selecionado o capítulo intitulado Les trois préens de M. d'Artagnan pére ${ }^{20}$. Notadamente, A Condessa de Salisbury e Os Três Mosqueteiros são narrativas históricas elaboradas no período que Meyer (1996) define como primeira fase do romance-folhetim: 1836 - 1850.

O padrão clássico de Vladimir Propp (2012), que é estabelecido na situação inicial e em 31 ações extraídas dos contos russos, foi utilizado como protocolo metodológico. Utilizando sua definição reduzida em uma palavra, as funções proppianas são: afastamento, proposta ou proibição, transgressão, interrogatório, informação, ardil, cumplicidade, dano ou carência, medição, início da reação, partida, primeira função do doador, reação do herói, recepção do objeto mágico, deslocamento entre dois espaços, combate, marca, vitória, reparação do dano, regresso,

19 Publicação original disponível em: <http://gallica.bnf.fr/ark:/12148/bpt6k426734n>, acesso em 07.04.2015 20 Publicação original disponível em: <http://gallica.bnf.fr/ark:/12148/bpt6k721099p.r=Le\%20Si\%C3\%A8cle\%20 :\%20journal\%20politique,\%20litt\%C3\%A9raire.langFR>, acesso em 07.04.2015 
perseguição, salvamento, chegada incógnita, pretensões infundadas, tarefa difícil, realização, reconhecimento, desmascaramento, transfiguração, castigo e casamento. O método permite vislumbrar a organização da narrativa e o momento em que se propõe seu corte. Além das funções proppianas, a tríade "expectativa", "resultado" e "brecha" de Robert Mckee (2006) foi aplicada para definir efeitos de sentidos propostos pelo gancho. Espera-se por algo e quando o resultado não é atingido, gera-se o estado de atenção.

\section{Resultados e discussões}

Na leitura da organização da história de A Condessa de Salisbury com Propp (2012), encontrou-se como situação inicial a paz em Londres. Suntuosamente, foram apresentadas as personagens em suas ações rotineiras no Palácio de Westminster. De acordo com Propp (2012, p.28), ela "dá a descrição de um bem-estar particular, por vezes sublinhado propositalmente" e "serve, evidentemente, de fundo contrastante para a adversidade que virá a seguir". A superação da normalidade é construída com as funções afastamento, proposta, transgressão, interrogatório, informação, ardil e cumplicidade. Essa linha de acontecimentos pode ser sintetizada com a premissa: é efetuada uma proposta, seu promotor se afasta, o que possibilita o não cumprimento, uma transgressão. O conhecimento da transgressão se dá por meio de interrogatório que culmina com a obtenção da informação. No processo, o antagonista age ardilosamente e o protagonista não percebe essa ação, tornando-se cúmplice. Ao final, tem-se o conflito ou dano que, quando anunciado torna-se mediação, que deverá ser reparado com a história. No primeiro capítulo que é analisado não foi encontrado a sequencialidade completa, apenas a transformação da informação em ardilosidade e em cumplicidade. Robert de Artois age a partir do conhecimento sobre o parentesco de Edward II com o rei da França para mudar o posicionamento dele quanto ao direito do rei inglês ao trono francês. $O$ ato gera a declaração pública de guerra à França, a mediação de um dano que desequilibrará a situação inicial. Essa desarmonia foi real e é conhecida como Guerra dos Cem Anos (1337-1453).

Em meio a discussões sobre a partida das tropas francesas, uma 
carta é recebida. O romance-folhetim encerra-se com a seguinte passagem extraída do jornal: "Neste momento, a porta se abriu e um arauto aproximou-se de Edward dizendo que um mensageiro tinha acabado de chegar de Flandres"21 (DUMAS, 1836, p. 03, tradução nossa). A natureza dessa mensagem determinará os rumos da partida. Conforme já exposto, a introdução imprevisível da carta no romance pode ser definida como golpe de teatro. O conteúdo da mensagem pode adiar ou adiantar a guerra contra a França. O rei demonstra facilidade em invadir Auvergne e Flandre, mas a carta poderá revelar uma aliança com esses territórios. O público anseia por saber o que ocorrerá.

O capítulo do romance-folhetim foi publicado em três rodapés, sendo que cada um foi dividido em três colunas. Cerca de seis colunas apresentaram só diálogos, como característica prepoderante do gênero, além da construção histórica. No trecho, o rei é o protagonista e Robet é o antagonista. Porém, Alix de Granfton, a condessa de Salisbury por quem Edward nutre uma paixão, é a vítima. O rei acaba assumindo a posição de antagonista na vida da moçoila quando o conde Erl Salisbury tornou-se refém no coflito armado com resgate adiado propositalmente. Entre outras características citadas por Meyer (1996) e que foram notadas na obra estão a tipificação das personagens, a heroína pura, a vingança do herói, o suspense e o desfecho punidor, considerando a obra completa. A história é extensa e embora centre em figuras reais, o título do romance-folhetim força o direcionamento do olhar para a Condessa.

Tabela 01- A situação narrativa de gancho em La Contesse de Salisbury

\begin{tabular}{|l|l|l|l|}
\hline \multicolumn{1}{|c|}{ Expectativa } & \multicolumn{1}{|c|}{ Resultado } & \multicolumn{1}{c|}{ Brecha } & \multicolumn{1}{c|}{$\begin{array}{c}\text { Efeito de Sen- } \\
\text { tido }\end{array}$} \\
\hline $\begin{array}{l}\text { Edward III declara } \\
\text { guerra à França e } \\
\text { seus aliados. }\end{array}$ & $\begin{array}{l}\text { Edward III recebe } \\
\text { a comunicação de } \\
\text { um reino hostil. }\end{array}$ & $\begin{array}{l}\text { Qual é a natureza } \\
\text { da mensagem? } \\
\text { Poderá adiantar } \\
\text { ou postergar o } \\
\text { conflito? }\end{array}$ & $\begin{array}{l}\text { Surpresa } \\
\text { Curiosidade }\end{array}$ \\
& & & \\
\hline
\end{tabular}

21 Texto original: "En ce moment, la porte de la salle s'ouvrit, et un héraut s'approchant d'Édouard lui annonça qu'un messager venait d'arriver de la part de Jacques d'Artevelle, de Flandre". 
A título de comparação do gancho, observou-se Os Três Mosqueteiros, destacando a partida de D'Artagnan em busca do chefe dos mosqueteiros, M. de Tréville, amigo de seu pai no primeiro capítulo. Nesse trecho, o jovem recebe um cavalo de presente. Há uma situação de carência ou situação inicial desequilibrada. A carência é vislumbrada em Propp (2012) como uma forma de dano. Ao chegar à aldeia de Meug, D'Artagnan é provocado ardilosamente por um fidalgo que deprecia o cavalo recém-ganhado do pai. D'Artagnan tenta agredir o fidalgo, sendo coibido por seus homens, a cumplicidade. Ao revistá-lo, o fidalgo e seus homens intuem que o jovem é protegido do chefe dos mosqueteiros, situação que lhes poderá causar um dano.

Tabela 02- A situação narrativa de gancho em Le Trois Mousquetaires

\begin{tabular}{|c|l|l|l|}
\hline Expectativa & \multicolumn{1}{|c|}{ Resultado } & \multicolumn{1}{c|}{ Brecha } & $\begin{array}{c}\text { Efeito de Sen- } \\
\text { tido }\end{array}$ \\
\hline $\begin{array}{l}\text { Demonstrar supe- } \\
\text { rioridade e poder a } \\
\text { um desconhecido }\end{array}$ & $\begin{array}{l}\text { Agride-se o prote- } \\
\text { gido do chefe dos } \\
\text { mosqueteiros }\end{array}$ & $\begin{array}{l}\text { Quais serão as } \\
\text { consequências da } \\
\text { agressão? }\end{array}$ & $\begin{array}{l}\text { Curiosidade } \\
\text { Nova direção }\end{array}$ \\
\hline
\end{tabular}

O gancho apresenta um reconhecimento, situação que confere ao desconhecido uma importância: "- Uma carta endereçada ao Senhor de Tréville, capitão dos mosqueteiros - É verdade? - Vos digo com honra que sim, excelência"22 (DUMAS, 1844, p. 02, tradução nossa). Em ambas as situações apresentas, um elemento novo é inserido na história, gerando o estado de atenção que possibilita a interrupção.

\section{Considerações Finais}

Neste trabalho de averiguação e de leitura de marcos fundadores que geralmente não são analisados, tentou-se superar equívocos e informações desencontradas que são replicadas, como suas obras iniciais e a data da sua gênese, indicando que o folhetim, como uma coluna de natureza multifacetada e desprezada em detrimento ao seu romance,

22 Texto original:“.- Une lettre adresséc à M. de Tréville, capitaine des mousquetaires. - Eu vérité? - C'est comme j'ai I'honneur de vous le dire, excellence". 
surgiu no dia 28 de janeiro de 1800 no Journal des Dèbats a partir do aumento do tamanho do papel de impressão do periódico. Foram apresentadas notas sobre a origem e a consolidação, constituídas através da observação nas páginas dos jornais, considerando o período inicial, que é negligenciado pelos estudos desse gênero. O fenômeno literário tornou-se matriz de linguagem importante que resistiu durante diferentes momentos políticos na França e que perpassa até os dias atuais em outras formas de elaboração de histórias; uma referência ou modelo que tem norteado as criações narrativas.

No exame dos capítulos de A Condessa de Salisbury (1836) e de Os Três Mosqueteiros (1844), romances confeccionados pelo escritor Alexandre Dumas, as estratégias empregadas para interrupção e para instauração de gancho foram vislumbradas, técnicas que resistiram ao tempo e que são utilizadas atualmente no romance-folhetim audiovisual de maior prestígio no país: a telenovela. Da alteração da extensão da folha do papel às experimentações no espaço extra, o termo "folhetim" tornou-se sinônimo de apenas uma de suas publicações, o romance seriado, ainda que tenha sido um espaço de textos diversos: crítica teatral, livros, revistas, discussões filosóficas, enigmas, charadas, vendas, avisos e outras publicizações.

\section{REFERÊNCIAS}

ARISTÓTELES. Poética. Porto Alegre: Editora Globo, 1966.

BORY, Jean. Louis. Premiers éléments pour une esthétique du roman-feuilleton. Tout feu, tout flamme. Paris: Julliard, 1966.

CAZANI JÚNIOR, Luís Enrique. Da veiculação em fluxo contínuo para a disponibilização: o gancho na produção de sentido da telenovela Avenida Brasil. Dissertação de Mestrado. Universidade Estadual Paulista "Júlio de Mesquita Filho", Bauru, 2016. Disponível em: <https://repositorio. unesp.br/handle/11449/143799>, Acesso 26.07.2017.

CAZANI JÚNIOR, Luís Enrique. O fenômeno do gancho: a tensão e a interrupção. Revista Mediação. V. 18, n. 23, 2016.

DUMAS, Alexandre. La Contesse de Salisbury. La Presse. v.1 n.15 p.1-3, jul/1836.

DUMAS, Alexandre. Le Trois Mousquetaires. Paris. Le Siècle. v.9 n.78 p.1-2 mar/1844.

ECO, Umberto. Apocalípticos e Integrados. São Paulo: Perspectivas, 2008.

HAUSER, Arnold. História social da literatura e Arte. São Paulo: Martins Fontes, 1972. 
MCKEE, Robert. Story: substância, estrutura, estilo e os princípios da escrita de roteiro. Curitiba: Arte \& Letra, 2006.

MEYER, Marlyse. Folhetim: uma história. São Paulo: Companhia das Letras, 1996.

MOISES, Massaud. Dicionário de termos literários. São Paulo: Cultrix, 2013.

PARTINGTON, Charles. Frederick. The British Cyclopaedia of the Arts, Sciences, History, Geography, Literature, Natural History and Biography. Volume III. London, 1837.

PAVIS, Patrice. Dicionário de Teatro. São Paulo: Perspectiva, 2011.

PLON, E; NOURRIT. Le Livre du centenaire du Journal des Débats 1789-1889. Disponível em: <http://gallica.bnf.fr/ark:/12148/bpt6k480221d >. Acesso 07.04.2015

PROPP, Vladimir. Morfologia do conto maravilhoso. Rio de Janeiro: Forense Universitária, 2012.

RIBEIRO, José Alcides. Imprensa e ficção no século XIX: Edgar Allan Poe e a narrativa de Arthur Gordon Pym. São Paulo: Editora da UNESP, 1996.

Data do recebimento: 28 fevereiro 2019

Data da aprovação: 08 abril 2019 


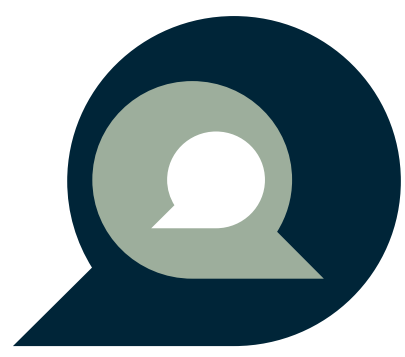

